\title{
Discurso do Orador da Turma de Bachareis de 1937
}

Proferido na solennidade da collação de grau realizada, em 18 de janeiro de 1938, no Theatro Municipal de S. Paulo.

\section{Ricardo Wagner}

Neste mundo inquieto e surdo ás supplicas de paz, nesta America nova, mas de largos horizontes, neste Brasil inexperiente, mas acalentando esperanças num futuro luminoso, vale a pena ser advogado?

Colhem, porém, as interrogações, que levantámos? Ou, antes deveriam formula-las sociologos, historiadores e philosophos?

Dizemos que sim, que o advogado pode não só propolas, como responde-las, que advogado não é apenas o que interpreta, mas o que faz a lei, quando no exercicio dos postos de administração publica.

Dizer que o advogado é somente o classico "defensor da viuva e do orphão", ou o que estabelece relações entre os casos concretos e as leis, é linguagem extranha aos nossos ouvidos.

A razão é que, o estado actual do mundo impoz aos que deixam agora os bancos de uma academia de Direito, porque são advogados e porque são moços, a investigação de problemas, de cuja solução decorrem consequencias de varia 
especie, entre as quaes a do caracter da nossa profissão e a definição da somma de direitos e deveres, que se lhe attribuem.

Fique, pois, aos rabulas, que vegetam no terra-terra das letras juridicas, a funcção somenos de tratar exclusivamente a legislação positiva. Fique aos causidicos de poucos quilates, que se disputam a primazia de melhor collocar virgulas nos textos de leis, ou de chamar periodos á ordem directa, a missão incolor de litigar pleitos, pelo ruido das palavras e não pelo valor dos argumentos. Fique aos leguleios o papel apagado de olhar a lei na sua face externa, sem procurar os motivos que a determinaram, as correntes doutrinarias que a inspiraram e as circumstancias propicias, que lhe favoreceram o apparecimento.

Não vae nisso menosprezo algum ao conhecimento da applicação do Direito na pratica, condição essencial do triumpho definitivo na advocacia.

O que desejamos é que o Direito não seja sophismado pelos que lhe conhecem a fachada, sem lhe penetrar os fundamentos.

o que queremos é accentuar o encargo de relevo que cabe, no presente, ao advogado, o peso das responsabilidades que o assaltam, e, por conseguinte, a grandeza da profissão, que abraçámos.

Compete-lhe, hoje, uma funcção social, proveniente da funcção social que desempenha o Direito. Os que quizerem saber do papel do advogado, que respondam a esta pergunta - "em todos os tempos e em todos os logares, quem fez e faz as leis, que reflectem o Direito?" Ora, o Direito na feliz definição de Pedro Lessa "é a sciencia que tem por objecto o conjuncto organico das condições de vida e desenvolvimento do individuo e da sociedade, dependentes da vontade humana, e que é necessario sejam garantidas pela força coercitiva do Estado"

Si é certo que a lei não modifica "as condições de vida e desenvolvimento do individuo e da sociedade", mas, ao 
contrario, taes condições é que influirão no animo dos legisladores na elaboração das leis, então mais espinhosa, mais complexa é a missão do advogado.

Nesse sentido, tem que ser, a um tempo, sociologo, históriador e jurista. Quando analysa os factos sociaes, apanhando-lhes os traços especificos, quando disseca a sociedade para a qual vae legislar, é sociologo.

Quando investiga os acontecimentos passados, em relação ás causas que os produziram e ao meio, em que se desenrolaram, é historiador.

Quando, depois de colher os elementos que as investigações anteriores lhe proporcionaram, traça para determinado povo normas de Direito, é jurista. Diria, alguem, um sorriso sceptico nos labios, que nós, jovens advogados, não penetrassemos outras provincias do saber humano, e que ao estudo das leis deveriamos limitar nossas actividades. E accrescentaria: aos advogados de outras eras não preocupavam as questões sociaes.

Ora, naquelle tempo, quando os homens de sciencia, talvez presumpçosamente, mas sem duvida bem intencionados, ensaiavam ainda os primeiros passos no proposito de encontrar para todas as incognitas soluções scientificas, e em virtude disso, crearam este mundo de perfis indecisos, que nos legaram, naquelle tempo tudo parecia estavel, definitivo e indestructivel. Variando embora de nação a nação, as formas de governo dir-se-iam consolidadas de vez. Nenhum movimento de grande envergadura ameaçava as velhas civilizações. Nenhuma guerra capaz de abalar o mundo absorvia a attenção dos conductores de povos. Uma suave paz de espirito envolvia os homens. Estes, dominados por uns restos de sentimentalismo piégas namoravam, horas a fio, os olhos vidrados de lagrimas, os versos chorosos de uma poesia lyrica. Si bem que vazia de belleza e de sentimento, a poesia arrancava applausos da critica, si apertada no "sapato chinez" do soneto. 
Fechados na torre de marfim, de suas creações cerebrinas, os escriptores viviam isolados do mundo e de seus problemas.

$\mathrm{Na}$ oratoria, o que impressionava era o palavreado ramalhudo e pomposo, acompanhado de gestos de ribalta. Era ainda o tempo de excessivo formalismo.

Formalismo, que anquilosava o proprio Direito, e do qual continuamos escravos. Era o tempo - bom tempo talvez aquelle - em que os homens se entregavam aos lazeres espirituaes, porque lá fóra ventos bonançosos sopravam. Não se carreavam para os livros themas, que fallassem dos destinos dos homens e das nações, porque já teriam encontrado a estrada segura, pela qual trilhavam. O dia de amanhã era a repetição do dia de hoje. No campo juridico notae snrs. - era possivel prever, isto é, verificadas taes relações de Direito, seriam regidas por taes leis e obedeceriam a taes principios.

Ora, vivendo nesta atmosphera de paz, sob o dominio de doutrinas incontestaveis na esphera do Direito, não admira attrahisse o advogado senão o seu estudo ou, de quando em quando, a arte pela arte.

Agora, mudaram-se as coisas. Revolveram-se nos alicerces as formas de governo. A guerra de 1914 iniciou um novo periodo na Historia. Ha uma generalizada inquietação de espirito. Os homens, si ainda choram, não é pelo lyrismo das poesias plangentes, mas pelos dramas torturantes de origem espiritual e material, que assoberbam o mundo. A literatura gravita em torno das theses sociaes. Nas manifestações da intelligencia, o que se procura é um pensamento orientador, é o esboço de um caminho a seguir, é uma resposta ás graves interrogações de nosso espirito. Não ha tempo para o polimento esmerado da phrase. Mas deseja-se um escrever correcto, um estilo leve e despretencioso, sem derramamento vocabular. Na oratoria, o que se visa, é a simplicidade, é a clareza, é a sobriedade. Abreviar é a ordem de commando. Proscripção dos formalismos superfluos, principalmente no processo. Mas bate-se pelo 
conhecimento perfeito da technologia juridica, chave com que se abrem as portas dos institutos de Direito. Ignora-se o que será o dia de amanhã. Dada certas novas relações de Direito - notae snrs. - desconhecem-se as leis e os principios que vão regula-las.

Ora, o advogado dessa epoca soffreria, como soffre, directa ou indirectamente, sua decidida influencia. Tinha que se pôr em contacto com phenomenos anteriores ao phenomeno juridico. Porque é mister insistir na verdade, de que o Direito não é causa mas effeito de um complexo social. O gráo de civilização de um povo é que subordina sua estructura juridica, mas esta nunca produz civilisação. Que mal haverá, em que nos appliquemos simultaneamente com o estudo do Direito a outros de natureza diversa, agora, que o paiz passa por transformações radicaes, afim de que encontremos soluções adequadas para os problemas do Brasil? Para que as mais altas concepções juridicas não se sepultem nos livros, o primeiro trabalho é arrotear o terreno. Antes de tudo, pois, o Brasil precisa crescer. Crescer de dentro para fóra. Crescer, engrandecendo-se. Façamos uma civilização massiça, a cujo natural desenvolvimento se amolde a forma de governo. Sob este aspecto, uma democracia real, adaptada ás condições ethnicas, mesologicas, historicas e politicas, é o regime ideal para o Brasil, porque mais flexivel e menos rigido que outro qualquer. Não tenhamos, porém, o culto cego das formas, que não passam, afinal de contas, de uma super-estructura, e tratemos do homem - "que é o fundo de tudo" - como lá diria o velho Michelet, de cuja instrucção e cultura politica resultam os bons governos. A nação, porque é um organismo vivo, precisa crescer biologicamente. Como os animaes e os vegetaes. Só os seres mortos "crescem" por sobreposição.

Mas, em que consiste a funcção social do advogado?

Consiste em verificar a contribuição dos institutos de Direito, através dos tempos, na evolução do paiz, notando os que lhe promoveram ou empeceram o progresso. Consiste em indagar do homem brasileiro, suas condições de vi- 
da, seu nivel de instrucção, as reacções que apresenta deante dos acontecimentos politicos, distinguindo o que ha nellas de permanente do que é transitorio. Consiste, por essencia e por excellencia, em dar ao homem a firme convicção de que $o$ interesse individual jamais sobreleva aos interesses collectivos.

Social, porém, é um vocabulo, cujo sentido varia com o palco, que lhe serve de acustica. Na França da intelligencia, onde o espirito em tudo impera; na Russia orientalizada e illetrada, presa nos circulos de ferro de seus usos e costumes extranhos á civilização do occidente; na Inglatterra tradicionalmente liberal, onde o culto do passado assume ares de mysticismo religioso, o adjectivo social junto do substantivo missão, significaria, talvez, respectivamente, intellectualizar as massas, abolir as classes e conservar a tradição. Bem outro, entretanto, é o sentido desse "social" tão sovado, quando pronunciado no Brasil, onde, affirma o arguto Luc Durtain "os homens actuam menos por suas obras do que por força de sua intima e secreta substancia" Focalizar a terra e o homem é traduzir-lhe o significado, pois é recolher o material e o instrumento com que solucionar problemas do Brasil.

Quanto á terra, della fallaremos, de caminho, em largos traços. Vae longe o tempo, em que se acreditava piamente que a natureza esmaga o brasileiro, que é della servo e nunca senhor. Muito menos se levaria a serio o conceito de Buckle de que "os ventos aliseos concorriam para impossibilitar o advento de uma grande civilisação no Brasil"

O sr Ovidio da Cunha em recente publicação "A America e o Mundo" situou muito bem o homem deante da natureza americana. "Na Europa, diz elle, o homem afastouse completamente de meio physico; na Asia o homem permaneceu numa posição estatica; na Africa a natureza venceu o homem; na America a natureza fundiu-se com o homem de modo que nem o homem vence o "habitat" nem tão pouco é esmagado pela sua exhuberancia cosmica" No Brasil, poucas regiões inhospitas e estereis seriam ferteis e 
promissoras, mesmo na falta de um Nilo providencial, si o trabalho humano armado de instrumental technico lhes modificasse a physionomia. Nosso meio physico, pois, não modela os inertes, os rebeldes, os desilludidos. Que as leis não façam o que não faz a natureza .

Quanto ao homem, seu estudo sobe de interesse, porque atravez delle se esclarecerão causas, na apparencia inextricaveis, de transformações historicas e sociaes. $\mathrm{O}$ homem polariza, hoje, a intelligencia pensante. Attribue-se-lhe o movel dos grandes movimentos politicos. Da-se-lhe na Historia contemporanea um logar de vulto. Nunca, mais do que agora, acredita-se que as instituições valem o que valem os homens, que as encarnam. Governos só se impõem quando trazem á frente um nome de escol, que brilha pelo pensamento, pela acção e pelo caracter, pois que muito dessa crise que perturba o mundo é crise moral. Temem-se as duplas personalidades, aquellas que teriam inspirado o grande orador sacro neste trecho do Sermão da Sexagesima; "entre o semeador, e o que semeia - diz o Padre Vieira ha muita differença: uma cousa é o soldado e outra cousa o que peleja; uma cousa é o governador e outra o que governa. Da mesma maneira, uma cousa é o pregador e outra o que prega" E adeante "o melhor conceito que o pregador leva ao pulpito, qual cuidaes que é? E' o conceito que de sua vida têm os ouvintes". O homem é tudo. Eis a razão por que as biographias são esquadrinhadas com sofreguidão pelas multidões ledoras. Eis o motivo por que Alex Carrel se tornou mundialmente fallado, com o famoso "L'homme cet inconnu" Mas não se diga que só nos estados totalitarios, onde o chefe deixa a sua marca pessoal indelevel, e não nas democracias interessa o estudo do homem. Por ventura, a democracia norte-americana, nestes annos, não é caracteristicamente "rooseveltiana"

Ora, se o homem é o nucleo das organizações politicas, quer na direcção, quer como elemento dellas, vejamos o homem brasileiro. Sobejam-lhe qualidades no trabalho de elevar o Brasil. Duas dellas é mister encarecer. 
A primeira é a alma - faça-se desta o conceito que aprouver - alma privilegiada da nossa gente, que foge ao materialismo da vida contemporanea.

Alma que a technica, essa technica avassaladora, que buscou trazer a felicidade ao homem, neste seculo mechanizado e secco de vida espiritual, essa technica não sugou do homem brasileiro, a coisa intima, imponderavel, que sentimos dentro de nós, e que chamamos de alma. Alma, cuja existencia se percebe, por exemplo, no culto tributado pela nossa gente ás mais caras virtudes christãs, na conservação amorosa dos laços de familia.

Não é extravagante, snrs., a pretenção de querer enxergar nestes impulsos espontaneos e nobres, a prova de que o brasileiro ainda não se deshumanizou, e nisto demonstra que é um filho legitimo da America Latina.

Outro sentimento, a que nos referimos, e que nos é immanente, é "a bondade original e unica, phenomeno humano e sociologico, que não depende de nenhum decreto senão do decreto de Deus, que a instituiu no coração de todos nós", como accentuou ha dias, em notavel discurso o eminente sociologo de "O Brasil no original" Contam os que viajaram outras terras que não é thema de prelecção balofa essa virtude do homem do Brasil.

$\mathrm{E}$, na feitura das leis, não ha como esquecer este traço fundamental da nossa gente, não para contempla-lo com favor especial, o que seria ridiculo, mas para considera-lo como attenuante dos effeitos de rigidas disposições de lei, o que será natural e logico. O que cumpre, através das leis, é crear o meio dentro do qual o homem "se realise o mais possivel para realisar mais", pois ahi reside "o interesse social"

Do individuo o que se pede hoje é o trabalho, intellectual ou material, com fins sociaes, em favor da collectividade, graças á qual elle vive e vence. Mas essa consciencia de deveres sociaes elle só adquire quando sentir necessidade de transformar taes deveres em lidimos direitos sociaes, de 
cuja observancia lhe adveem beneficios varios. Portanto, só depois que se realise, depois que se torne individualmente capaz, é que socialmente será um valor positivo e efficaz dentro da communidade.

Ora, collegas, si a natureza é prodiga e não gera rebellados, si o homem é prestadio e dotado deste socialmente aproveitavel elemento affectivo, que é nossa typica bondade; si a machina, que revolucionou o seculo XX não conseguiu seccar aspirações alevantadas da nossa alma, aspirações, que devem ser conservadas porque são o melhor conteudo da felicidade collectiva dos povos, si assim é, a que atttribuir o relativo moroso desenvolvimento do Brasil, sinão a uma opposição flagrante entre as leis e as suas realidades?

Vale a pena ser advogado neste mundo inquieto e surdo ás supplicas de paz? Vale, para andarmos juntos com a nossa diplomacia, da qual a guerra não será nunca um prolongamento do campo de batalha, ao contrario do que das diplomacias, disse Clusevitz.

Vale a pena ser advogado nesta America Nova, mas de largos horizontes? Vale, para diffundirmos entre as nações o ideal sublime de americanismo, que é o da humanização do homem. Vale a pena ser advogado neste Brasil inexperiente, mas acalentando esperanças num luminoso futuro? Vale, para ajustarmos ás suas verdadeiras necessidades sociaes o seu mechanismo pclitico e juridico, meio seguro de torna-lo prospero e feliz.

E vale, sobretudo, pelo prazer sem par que desperta o convivio de intelligencia e de sentimento, feito entre professores e alumnos, á sombra gazalhosa da velha Academia de Direito!

Nas preces sentidas que nesta noite levantamos á memoria dos queridos companheiros de jornada Enio Bicudc de Almeida, Said Kalil, Fernando Amaral e Victorino Costa Vianna, ao inesquecivel Dr Julio Maia e aos preclaros professores Gama Cerqueira, Manoel Villaboim e Raphael Sam- 
paio, cujas mortes ainda chorámos, vão tambem, oh! gloriosa Academia, as reconhecidas homenagens de vossos filhos espirituaes!

$\mathrm{E}$, em vós, professor Jorge Americano, illustre, culto e dedicado paranympho da turma, saudamos a todos vós, mestres, a um tempo, de Direito e de Civismo, pelo pensamento e pelo exemplo, mestres que sois "semeadores", que semeaes, soldados, que pelejaes, pregadores, que pregaes" 